\title{
Neologistic Jargon Aphasia: A Case of Akala Gboo
}

\author{
Sopuruchi Christian Aboh \\ Department of Linguistics, Igbo and other Nigerian Languages, University of Nigeria, Nsukka, Nigeria
}

\begin{abstract}
This paper conducts a psycholinguistic analysis of a neologistic jargon aphasic, Akala Gboo (a pseudonym of the patient) who is 52 years old. Neologistic jargon aphasia is a type of language disorder that manifests in the form of fluent speech, production of series of meaningless sounds and formulation of new words. This aphasic condition has not been explored to a large extent by researchers. By adopting the descriptive research design and using oral interview as instrument of data collection, the research finds out that the jargon aphasic exhibits elements of phonemic and morphemic paraphasias; as well as production of new words which are very much meaningful to him but they sound as gibberish to the hearers such as kwotekumakumakakununism, inianimous kalikwokaminolamkamkwuu. The paper finds out that the stimulants of the jargon aphasic symptoms are excitement and excessive intake of alcohol and cigarette. However, the paper recommends that government agencies and Non-Governmental Organisations (NGOs) should set up an aphasia centre where the needs of aphasics will be catered for and which will also make them easily accessible for aphasia researchers.
\end{abstract}

Index Terms—neologism, aphasia, speech production, psycholinguistics

\section{INTRODUCTION}

Psycholinguistics is one of the major areas in linguistics that studies the interplay between language, the mind and the environment. In essence, psycholinguistics studies the relationship that exists between language and the mind; and language and the environment. Agbedo and Uchendu (2010) note that psycholinguistics covers the cognitive processes that make it possible to generate a grammatically and meaningful sentence out of vocabulary and grammatical structures, as well as the processes that make it possible to understand utterances, words, texts etc. They further note that an important focus of psycholinguistics is the largely unconscious application of grammatical rules that enable people to produce and comprehend intelligible sentences.

In the study of psycholinguistics, it takes cognizance of the linguistic abilities of normal human beings (language comprehension, language production, and language acquisition) and the language disabilities of human beings. For the purpose of this research, a glance will be taken on language disabilities of man. Language disabilities of man bring about language disorders. The predominant language disorder observed in humans is aphasia. Head (1926) defines aphasia as a disorder of symbolic formulation and expression as a result of brain damage. Agbedo (2009 p. 152) opines, "Aphasia is a communication disorder caused by brain damage and characterized by complete or partial impairment of language comprehension, formulation and use." He equally remarks that aphasia is also seen as the loss of normal language abilities as a result of some pathological condition.

However, aphasia is a language disorder that hinders the proper production, acquisition and comprehension of speech. Language disorder is a situation whereby the linguistic ability of human beings is not obtainable as required. Bishop and Rosenbloom (1987) aver that language disorders can be either receptive or expressive; receptive disorders refer to changes in understanding or processing language while expressive disorders include difficulty in putting words together, limited vocabulary or inability to use language in a socially appropriate (which neologistic jargon aphasia is a good example). Similarly, Agbedo and Uchendu (2010) contend that language disorders are often the earliest indicators of a learning disability; people with language disorders have difficulty producing speech sounds, using spoken language to communicate, or understanding what other people say, depending on the problem. They further note that the most common types of aphasia result from cerebro-vascular accidents (CVAS) generally referred to as 'strokes.' Expatiating on the possible causes of brain (left hemisphere) damage which in turn causes aphasia, Agbedo (2009, p. 154) notes:

Apart from the CVAs, there are other factors that can cause brain damage. These include microorganic invasion of brain cells, infections leading to infarctatrophied brain tissue, genetic disease typified by an interference with the neural development of the nervous that produces spina bifida, abnormal cell growth in the brain resulting in intracranial tumours, infectious diseases that affect the brain such as meningitis (the inflammation of membraneous covering of the brain and spinal cord) and poliomyelitis (the inflammation of the grey matter spinal cord).

Be it as it may, one thing to note is that the damage of the dominant hemisphere for language production manifests in the form of aphasia. It is in line with this that Yule (1996) asserts that aphasia is an impairment of language function due to localized cerebral damage, which leads to difficulty in understanding and/or producing linguistic forms. What 
Yule offers here is that there is a particular part of the brain that is responsible for language production and comprehension. The extremist view of the localisation theory avers that there is a strict one-to-one correspondence between the anatomical areas of the brain and functions of the body. Aitchison (1976) debunks the idea of brain localization by noting that all the available evidence relating to localization is derived from brain-damaged patients. He further remarks that direct correlation of wounds with speech defects cannot be made especially as a wound in one area of the brain can generate a ripple of repercussion in other areas. Reacting to this controversy, Agbedo (2009) remarks that further localisation within the left hemisphere remains controversial although certain sections of the brain and their underlying inter-connections seem more likely to be crucially involved in the production and comprehension of speech than other sections. However, the present researcher states to an extent, the dominant language hemisphere is responsible for linguistic activities.

Neologistic jargon aphasia is one of the types of aphasia. According to Bastian (1969), it is the production of series of speech without meaning. For Schwartz (1987), neologistic jargon aphasia is associated with a lesion site in the posterior temporal lobe of the dominant language hemisphere. Buckingham and Yule (1987) observe that the typical speech pattern of a jargon aphasic is fluent, easy articulated, and free of arthric qualities, etc. Agbedo (2009 p. 170) in his contribution on the characteristics of neologistic jargon aphasia, notes, "Nonetheless, the most visible feature of jargon aphasia is neologism, that is, novel word creations that sound bizzare and quite often described as nonsense or gibberish."

Similarly, Agbedo and Uchendu (2010, p. 35) observe, "Patients with present symptoms of neologistic jargon aphasia may substitute words unrelated semantically to their intended messages; and even produce words that mean nothing in the language but mean everything to them." From the research carried out by the scholars above, they equally observe that the patient produces fluent but long strings of jargon that sound like sentences but make no sense; that he makes intense effort to produce many words, that when he starts to talk in his super-fluency manner, he may not stop unless interrupted. They conclude that it is important to battle aphasia as it impacts an individual's life, now and into the future.

Some scholars have tried to classify neologism from the aphasia point of view but the predominant one is the classification provided by Schwartz (1987). According to him, neologisms are of three subtypes: the subtype that is synonymous with phonemic paraphasia, such that any word-like form produced that is not in the lexicon of the speaker's language; the subtype that contains recognizable pieces of real words from the speaker's language as in the monemic or morphemic; and the subtype that refers to a form with no identifiable source in the speaker's native language.

This last subtype is defined by Buckingham (1981) as phonological forms produced by the patient for which it is impossible to recover with any reasonable degree of certainty some single item(s) in the vocabulary of the subject's language as it presumably existed prior to the onset of the disease. The criticism of this classification is that neologism, according to Schwartz (1987), can only occur when the speaker is using his/her native language. But the reverse is the case with the patient under study where instances of neologism were seen when he was speaking in English which is not his native language but his second language.

However, attempts have been made in order to provide a number of possibilities for explaining neologisms. One of these is seen in Ellis (1985). He notes that they result from severe phonemic distortions of the underlying phonological forms of the target words. This implies, according to Agebdo (2009), that the jargon aphasic is able to retrieve an intended word or access its phonemic array before subsequent distortion by excessive phonemic paraphasias. In contrast, Buckingham and Kertesz (1974) postulate an anomic component to jargon aphasia such that a patient may not have in mind the word he desires at the time of neologism production. They note that it is possible that the hesitations (pauses) noted in jargon aphasics prior to neologisms indicate lexical access difficulties given that pausing represents lexical search and mental processing activity. This means that in an attempt to fill the pauses, the patient produces a bizarre sounds or words.

Secondly, another possible explanation to neologism as illustrated by Christman and Buckingham (1989) is the random segment or syllable generator. For them, the generator operated whenever form-based lexical retrieval was blocked and thus would function in conjunction with an underlying anomia. They further illustrate that if for example, a patient was unable to retrieve the phonological form of a word, he might search unsuccessfully until some critical period passed after which the device would begin to randomly construct a word for production in place of the intended lexical item. According to Agbedo (2009), the third proposed mechanism for jargon production considers neologism to be the result of a two-stage error. Phonemic paraphasia explanation assumes that the target word has been correctly selected but with subsequent distortion of that form by varying quantities of phonemic paraphasia leads to neologistic jargon aphasia.

The objective of this research is to identify the types of neologistic jargon aphasia manifested by the patient. The scope of this research is limited to only one neologistic jargon aphasic. This is because it is a herculean task to adopt all jargon aphasic in this research. As such, the chosen respondent represents the population sample. The significance of this work is that it will add to the literature on neologistic jargon aphasia.

\section{LITERATURE REVIEW}


This section reviews different psycholinguistic theories and related empirical researches carried out by researchers. The review of literature ends with summary of the literature review.

\section{A. Theoretical Studies}

\section{Behaviourism}

Behaviourism as a theory is spearheaded by Skinner (1957) in his Verbal Behavior. In his Verbal Behavior, Skinner made a large contribution to research into instrumental conditioning, and into directing the learning process. In instrumental conditioning, the learner is much less at the mercy of external stimuli. His actions and reactions, according to him, seem to come from within, as if at random. Skinner called such instrumental reactions 'operants.' He further notes that they serve to manipulate the environment in order to affect a change. Skinner believes that a learner can learn if his or her behaviour is shaped in the correct position.

According to the behaviourists, there are no innate ideas in the mind that are not products of the environment because for them, environmental factors condition man to a specific type of behaviour. This implies that a child who is acquiring language is molded by the experiences he/she undergoes. In essence, the standpoint of the behaviourists is that a child acquires language the same way he/she acquires other behaviours. As a result, they see language as a 'conditioned behaviour' anchored on the stimulus response process: Stimulus $>$ Response $>$ Feedback $>$ Reinforcement. Thus, language is practice based. This is in line with Yule's (2010) assertion that during the first two or three years of development, a child requires interaction with other language-users in order to bring the general language capacity into contact with a particular language such as English. Aside this criterion of being in a linguistic environment where the behaviour will be fully learnt, he goes further to stress thus:

The child must also be physically capable of sending and receiving sound signals in a language. All infants make "cooing" and "babbling" noises during their first year, but congenitally deaf infants stop after about six months. So, in order to speak a language, a child must be able to hear that language being used. By itself, however, hearing language sounds is not enough (Yule, 2010 p. 171).

From the above excerpt, it can be observed that the behaviourists believe that language has a relationship with the society. In other words, language influences the society and the society in turn influences language. This stance can be likened to the social approach to language development. Therefore, as it relates to this study, individuals that imitate the speech productions of a neologistic jargon aphasic.

\section{The mould and cloak theories of language and thought}

There are discussions on the relationship that exist between language and thought. On the one hand, language is said to condition thought. On the other hand, thought is said to condition language. Akwanya (2007) in his Language and the Habits of Thoughts claim that language is not primarily made for communication but for thought. Nwaozuzu (2013) contends that man thinks in language more than the way he speaks language. According to her, this explains the reason humans are said to be 'men of few words' and not of 'few thoughts.' However, within the general context of linguistic theory, the two theoretical accounts of the relationship between language and thought are: the mould and cloak theories.

The cloak theory postulates that language is clothed in thought. This implies that thought conditions language. In essence, language is a product of thought. On the other hand, mould theory postulates that language is a mould where thought categories are cast i.e. language conditions thought because man can only think with a language. The SapirWhorfian hypothesis, which is currently referred to Whorfianism is a major component of the mould theory. Whorfianism is divided into Linguistic Determinism, which emphasizes on the role of language in determining one's thought processes and difference in language equals different in thought processes or philosophy and the Linguistic Relativism, which focuses on the cultural symbols embedded in a language.

Language-culture relationship is attributed to Edward Sapir and Benjamin Lee Whorf (1897-1941) which is well known as the 'Sapir-Whorf Hypothesis.' Edward Sapir first propounded this hypothesis in his Language: An Introduction to the Study of Speech but it was further developed and popularised by Benjamin Lee Whorf in 1929. This hypothesis states that certain thoughts expressed in one language cannot be understood by those who use another language and that the way one thinks is strongly affected by one's native language. Thus, some concepts are untranslatable.

Sapir proposes that learning to walk is different from learning to communicate through language. As walking is a genuine biological function of all human beings, any individual child would learn to walk irrespective of any cultural background; but the child would learn to communicate ideas only according to the particular system of a particular society. This argument is related to Skinner's behaviourism. Sapir contends that if the child is removed from his respective society and transplanted in an alien society, his speech would be completely different from the speech of his original society and would be shaped by the new environment. Sapir's close associate and student, Benjamin Lee Whorf, carries forward the former's thesis on language and culture. Whorf throws critical light on the relationship between language and thought and suggests that man's perception of the world and his ways of thinking about it are deeply influenced by the structure of the language he speaks. Whorf's in-depth study of languages such as Hopi, Aztec and Maya gives him the idea of how the thought process of the speakers of these languages is related to the linguistic structure. 
Thus, one's life is shaped by the structure of language into specific ways of approaching reality. Whorf says that fluency in any language does not necessarily imply linguistic knowledge. To understand a language, one has to know its background phenomena, its systematic processes and structure. However, the "Linguistic Relativity" principle suggests that thought and perceptions of a speaker are determined by his language. As such, the Linguistic Relativist principle is for approaching each language entirely on its own terms. Language is constituted by grammar but it goes beyond grammar. In its symbolic organisation of the world, it is a mirror where culture is reflected. Yule (1996) defines SapirWhorf Hypothesis as language (that is, grammar) constitutes the means with which individuals think and therefore, especially as stated in its strongest form, language (that is, grammar) conditions or determines cultural thought, perception, and world view. The worldviews that one forms are determined by one's language which implies that every language carries with it the culture's system of values upon which its social, economic, and political discourses are formed.

Therefore, as it concerns neologistic jargon aphasia, the cloak and mould theories come into play because repressed thoughts result in the production of series of incomprehensible speech sounds. Due to the fluency of the jargon aphasic, he decides to speak, even though meaningless, than to pause in his speech. More so, whatever he communicates is conditioned by the linguistic though processes embedded in his language.

\section{Innatist theory}

Innatist theory is fall out of Chomsky's review of Skinner's Verbal Behavior. In the review of Skinner's book, Chomsky (1959) criticises Skinner's behavioural standpoint. He was the first to express his criticism. He remarks that with a finite number of linguistic rules, we can produce an almost infinite number of correct linguistic utterances. For example, the production of a completely new sentence cannot be explained by referring to acquired stimulus-response relationships. Children are able to produce sentences that they never heard before quite early in language development. $\mathrm{He}$ is equally of the opinion that they naturally make grammatical errors, but these errors are not so serious that we cannot understand what they are saying. Linguists believe that human beings may have an innate ability to apply the syntax - the grammatical arrangement of words in sentences - of a language.

This criticism and review led to a new approach of investigating language development which sees language from the standpoint of mental endowment and not behaviour. The cognitive or innatist approach to language development posits that children are born with an innate propensity for language acquisition, and that this ability makes the task of learning a first language easier than it would otherwise be. Chomsky remarks that every child has a Language Acquisition Device (LAD) in his brain, which makes him to generate a lot of acceptable sentences. For him and other cognitivists or mentalists, language learning or acquisition is too complex to be seen as a form of habit formation. More so, meaning to the cognitivists is very crucial to the acquisition, teaching and learning of language. They believe that for the structure of language to be learned, language acquisition and learning should be meaning based.

The position of Chomsky's innatism is not left uncriticised. The concept of LAD, is in controversial manner, and it was not supported by evolutionary anthropology which shows a gradual adaptation of the human body to the use of language, rather than a sudden appearance of a complete set of binary parameters. This criticism led some scholars to form the middle of the road approach as stated by Agbedo (2009). They posit that language acquisition and development take place with both the presence of the innate ability and the environment. It then goes without saying that a lesion in the brain is one of the causes of neologistic jargon aphasia.

\section{B. Empirical Studies}

Agbedo and Uchendu (2010) examined language disorders in two children, which neologistic jargon aphasia is one of the language disorders examined. The paper sought to reveal the linguistic properties of aphasics. The study observed that patients with present symptoms of neologistic jargon aphasia may substitute words unrelated semantically to their intended messages; and even produce words that mean nothing in the language but mean everything to them. From the research carried out by the scholars above, they equally discovered that the patient produces fluent but long strings of jargon that sound like sentences but make no sense; that he makes intense effort to produce many words, that when he starts to talk in his super-fluency manner, he may not stop unless interrupted. They concluded that it is important to battle aphasia as it impacts an individual's life, now and into the future. Though Agbedo and Uchendu (2010) and the present work are interested in neologistic jargon aphasia, they differ in the patients used.

Uchendu (2010) worked a psycholinguistic analysis of language disorders in selected aphasics. The study focused on the language impairments of two individuals: Ekene Ifejika and Chukwudi Onuorah aged 22 and 28 respectively. The study discovered that Ekene's overall cognitive disposition is generally characterised by disordered, fluent sound substitutions, and incomprehensible speech, which are symptoms of jargon aphasia. On the other hand, Chukwudi manifested symptoms of Broca's aphasia, is characterised by short, nonfluent speech, meaningful fragmented phrases that are produced with great efforts. Findings from the study indicated that aphasia impacts each individual differently, depending on the causes of the brain damage, the area of the brain that is damaged and produces different side effects in an individual's comprehension and speech; it may be genetic. The study concluded that language impairments, which these individuals present put them at risk for later general academic difficulties and therefore require immediate intervention programmes as well as the therapeutic expertise of the speech language pathologists. Uchendu (2010) focused on jargon aphasia and Broca's aphasia but the present research centres only on neologistic jargon aphasia. 
Ezeudo (2019) researched on stuttering and its associated behaviours in a stutterer from the psycholinguistic perspective. The aim of this study was to examine the phenomenon of language use in a male adult stutterer in Anambra state. Specifically, the study ascertained the psycholinguistic features in oral verbal language of stuttering from a phonetic, phonological, morpho-lexical, pragmatics and syntactic perspectives. The data for the study were obtained through observation and interview with the help of the mother and elder sister of the stutterer. The study adopted the Demand and Capacity theory and Packman and Attanasio's Dynamic Multifactorial model for analysis and also adopted a qualitative research design in examining the psycholinguistic effect of stuttering on the stutterer. The analysis of data revealed how the stutterer experiences "shell shocks" (trauma) of varying degrees, which are physically observed as secondary behaviour symptoms. The research also discovered that the respondent's stuttering is predominant in the sub lexical speech errors, (particularly; phoneme repetition, prolongations, blocks), in constituent boundaries. The respondent's stuttering also occurred in relation to initial sound, mostly within words, between words and at times rare at the end of sentences. His stuttered utterances showed reduced verbal utterances; and he stuttered on syntactic complex words, unfamiliar words, long words, and on content words. The study recommended that the federal government shall be involved in funding the training of speech pathologists. Ezeudo (2019) and the present study are related in the sense that they look at aphasic conditions but they differ because the former focused on stuttering whereas the latter is on neologistic jargon aphasia.

\section{Summary of the Literature Review}

Under the literature review, different theoretical postulations, which are related to the study, have been reviewed. They included behaviourism, the cloak and mould theories of language and thought and the innatist theory. The research also reviewed empirical researches that have been carried out on language disorders. From the review, the lacuna seen in the literature is that there is no research, to the best of the researcher's knowledge that has been completed as it regards neologistic jargon aphasia of a person over 50 years in Nsukka, Nigeria. This gap is what this research intends to fill.

\section{METHODOLOGY}

In this present study, the researcher with the help of two research assistants interviewed the language impairment of Akala Gboo. Suffice it to note that Akala Gboo is a pseudonym of the patient. This was chosen for security purposes. The research is purely a descriptive survey research design and unstructured interview was adopted as the method of data collection. This data obtained will be analysed qualitatively so as to X-ray the instances of neologistic jargon aphasia symptoms as well as identifying the type of neologism that occurs and to provide possible explanations of the occurrence. Due to the fact that the patient is a retired police officer, the researcher deemed it worthy to discuss police matters with him because it would make him to talk and to showcase jargon aphasic elements.

Akala Gboo is a retired policeman who hails from Opi in Nsukka Local Government Area, Enugu State. At the time of interview, he was 52 years old. His neologistic jargon aphasic condition started manifesting after his retirement. Features of jargon aphasia manifest when he is excited and engrossed in a discussion. With the help of two research assistants, his utterances were recorded, transcribed, and analysed.

\section{ANALYSis OF SPEECH}

As identified by Schwartz (1987 p. 172-173) that there are three types of neologism namely; 'phonemic paraphasia, such that the word-like form produced that is not in the lexicon of the speaker's language; the sub-type that contains recognizable pieces of real words from the speaker's language as in the monemic (i.e morphemic) paraphasias; the third subtype being the 'abstruse' neologism, one that refers to a form with no identifiable source in the speaker's native language.

However, the medium of the interview was English; though sometimes the patient code-mix with Igbo. There are elements of the first subtype, phonemic paraphasia by the aphasic. Examples of these words include: carriango, maliticious, tualasimical, biamizically, linel, annoted, and cele. These expressions are not in the lexicon of the English language nor Igbo. On the other hand, they were all coined by the aphasic as manifestations of neologistic jargon aphasia.

In the same vein, manifestations of morphemic paraphasias in the patient's speech were observed. These include: bulleted (From the word bullet which was used as a verb to mean shoot), wrong-fooled (used to mean disordered), marriage marricious (used to denote marriage activities), endeavourism (from the verb endeavour), Nwannemus (Igbo, used to denote my brother), givomize (give), levelism (to level), greasm my enjinol (lubricate my engine). The italicized words are the new words which were coined by the patient which are recognizable in the English/Igbo lexicon. The point of neologism lies in the addition of unaccepted affixes and functional shifts.

The last subtype of neologism as identified by Schwartz is also seen in the speech of the aphasic. These words or series of speech sounds has no identifiable source in either the Igbo or the English language. As observed, these series of speech sound without meaning may be meaningful to the aphasic but meaningless on the part of the listener(s). Examples of this series of speech sound without meaning include: kwotekumakumakakununism, inianimous 
kalikwokaminolamkamkwuu, nkwakoritamidokuminuimkwuinum, napinahushim, happininokumnikonuno...zim, mokwemimonokonoonkwikenism, kwichekinemi, kwichenomo, zikenimizim nankwo mi, izikemmino, etc.

The above examples are instances of meaningless series of speech sound. They do not have any meaning either in the English or Igbo languages. In the aspect of phonology, the manifestation of this last subtype tends to comply with the phonotactic rule of the Igbo language. This is so because the series of speech sounds obeyed the law of no consonant cluster and the rule of vowel or syllabic nasal ending in Igbo.

The emergence of neologistic jargon aphasia as observed in the patient is in line with Buckingham and Kertesz (1974) view that neologism has an aspect of anomic aphasia in it. This is evident in the speeches of aphasic because he does not just coin words. Rather, the new words emerged as a result that he has forgotten what he has in mind, thus leading him to creating new words in order to cover in for the silence already created. This anomic element is aphasic because Akala Gboo has passed the language acquisition stage and has acquired an adult language. If this anomic element occurs in a child, then it is not aphasic because the child is still undergoing the process of language acquisition. In all, neologism becomes aphasia of the speaker has acquired language, which presupposes that the words are there for him to use but decides to manufacture a new word.

In addition to the possible explanations of neologisms as discussed in the literature, at this juncture, the researcher observes that neologistic jargon aphasia can be stimulated by excitement and excessive intake of alcohol and cigarettes, thus; leading to the manifestations of the aphasic condition. This then implies that the patient's brain was damaged as a result of accumulated alcoholic and nicotine contents. It also points that his own aphasic condition was acquired and which manifested in the form of neologistic jargon aphasia.

\section{CONCLUSIONS}

This research has look into the psycholinguistic aphasic condition known as neologistic jargon aphasia with Akala Gboo as a case study. The research discovers that the subtypes of neologism as identified by Schwartz are manifested in the patient's speech. Also, the research discovers that neologism does not only occur in the speaker's native language, it also occurs in the second language of the speaker which is English. In explaining the possible reason behind the aphasic condition, the research discovers that there is an anomic component to it also notes that high intake of alcohol and cigarettes serve as major stimulants of the brain. Also, for the speaker; what he is saying has meaning but to the listener(s), they are meaningless. Inasmuch as neologistic jargon aphasia is seen from the negative point of view, I think that there are positives to be drawn. With the help of jargon aphasic, new words can be created in a given language and most often they are jargon/slang creators which with time spreads through their speech communities.

However, the researcher recommends that Non-Governmental Organizations (NGOs) and the Government should erect a structure where all those suffering from one aphasic condition or another should be kept and placed for rehabilitation. This will also help psychologists and psycholinguists to lessen the risks of going to the individual houses of this aphasic. Most often, threat to life is given when researchers seek to study a patient. On the other hand, these aphasics do not know the implication of their pathological condition, the intervention of NGOs and government will help to sensitize these patients and also find a way to reduce their plights.

Researchers in this area of study should not fail to employ the services of research assistant(s) so as to arrive at an adequate collection of data and provision of result. They should also observe the observer's paradox by making sure that their real identity is not revealed i.e. the main reason of the research so as to enable them gather original data.

\section{REFERENCES}

[1] Agbedo, C. U. \& Uchendu, A. G. (2010). Psycholinguistic analysis of language disorders: A case study of selected aphasics. Journal of Igbo Language \& Linguistics (JILL), 1(2), 31-39.

[2] Agbedo, C. U. (2009). Language and mind: New directions in psycholinguistics. Nsukka: ACE Publishers.

[3] Akwanya, A. N. (2007). Language and the habits of thoughts. Nsukka: Kraftz Publishers.

[4] Aitchison, J. (1976). The articulate mammal: An introduction to psycholinguistics. London: Hutchison \& Co. (Publishers) Ltd.

[5] Bastian, C. (1969). On the various forms of loss of speech in cerebral disease. British and Foreign Medical Surgical Review 45, 158-180.

[6] Bishop, C. V. M. \& Rosenbloom, L. (1987). Classification of childhood language disorders. In W. Yule \& M. Rutter (eds.) Language development and disorders. London: Mckeith Press.

[7] Buckingham, H. W. \& Kertesz, A. (1974). A linguistic analysis of fluent aphasia. Brain and language, 1, 43-62.

[8] Buckingham, H. W. \& Yule, W. (1987). Review: Phonemic paraphasias and psycholinguistic production models for neologistic jargon. Aphasiology, 1, 381-400.

[9] Buckingham, H. W. (1981). Where do neologism come from? In J. W. Brown (Ed.) Jargonaphasia (pp. 39-62). New York: Academic Press.

[10] Chomsky, N. (1959). Review of verbal behaviour by B. F. Skinner. Language 35, 26-58.

[11] Christman, S. S. \& Buckingham, H. W. (1989). Jargonaphasia. In C. Code (Ed.) The characteristics of aphasia (pp. 111-130). London: Taylor and Francis Ltd.

[12] Ellis, A. W. (1985). The production of spoken words: A cognitive neuropsychological perspective. In A. W. Eliis (Ed.). Progress in the psychology of language, 2, London: Lawrence Erlbaum Associates. 
[13] Ezeudo, C. (2019). Psycholinguistic study of stuttering in Anambra state. PhD seminar, Department of Linguistics, Igbo and Other Nigerian Languages, University of Nigeria, Nsukka.

[14] Head, H. (1926). Aphasia and kindred disorders of speech, 1\&2. Cambridge: Cambridge University Press.

[15] Nwaozuzu, G. I. (2013). Babelist theory of meaning. 72nd Inaugural Lecture, University of Nigeria, Nsukka.

[16] Schwartz, M. (1987). Patterns of speech production deficit within and across aphasia syndromes: Application of a psycholinguistic model. In M. Coltheart, G, Sartori, \& R. Job (Eds.) The cognitive neuropsychology of language. London: Lawrence Erlbaum Associates.

[17] Skinner, B. F. (1957). Verbal behavior. Cambridge: B. F. Skinner Foundation.

[18] Uchendu, A. G. (2010). Psycholinguistic analysis of language disorders: A case study of selected aphasics. M.A. dissertation, Department of Linguistics, Igbo and Other Nigerian Languages, University of Nigeria, Nsukka.

[19] Yule, G. (1996). The study of language (3rd ed.). Cambridge: Cambridge University Press.

[20] Yule, G. (2010). The study of language (4th ed.). Cambridge: Cambridge University Press.

Sopuruchi C. Aboh was born in Aba, Abia State on 20th November. He had his Bachelor of Arts Degree and Master of Arts Degree in Linguistics at the University of Nigeria, Nsukka. Sopuruchi specialises in sociolinguistics and pragmatics.

He has published some articles including: "The ideology of post-truth in Nigerian cities: A discourse historical analysis", Journal of Linguistic Association of Nigeria, 22(1), 64-78 and "A comparative analysis of lexical prepositions in the Ibibio and Igbo languages", Macrolinguistics, 6(9), 36-45.

Mr. Aboh is a member of Pragmatics Association of Nigeria, Nigeria Ecolinguistics Association, and Nigerian Institute of Translators and Interpreters. 